\title{
Estilo Feminino de Gestão em Empresas Familiares Gaúchas
}

\author{
Denize Grzybovski \\ Roberta Boscarin \\ Ana Maria Bellani Migott
}

\section{Resumo}

O estudo investigou o estilo de gerenciamento da mulher executiva nas empresas familiares de Passo Fundo (RS). Os princípios norteadores foram o gerenciamento transparente e as organizações de aprendizagem, focalizando as mulheres executivas. Essas apresentam características peculiares às organizações de aprendizagem. O objetivo foi identificar o estilo feminino de gerenciamento empresarial em empresas familiares, correlacionando-o ao perfil das mulheres gerentes. Foram investigadas 26 executivas, por meio de questionário exploratório e de entrevista semi-estruturada. Ficou evidenciado que as executivas das empresas familiares passo-fundenses cultivam valores, como a honestidade, a estima do ser humano e o companheirismo; permanecem atuando na empresa da família por amor à empresa; seus desejos e/ou sonhos pessoais estão relacionados aos sonhos e/ou desejos empresariais. Apresentam estilo de liderança mais voltado para as pessoas do que para as tarefas, porém são muito orientadas para o poder, assumindo postura gerencial mais baseada no modelo masculino de gestão.

Palavras-chaves: empresa familiar; executiva; gênero feminino; estilo de gestão.

\section{Abstract}

The study investigated the management style of the executive woman in the family-run enterprise in Passo Fundo, Brazil. The guider theories were the transparent management and the learning organizatios, focusing the executive women. They present peculiar characteristics to the learning organizations. The objective was identifying the feminine style of management in family-run enterprises correlating to the managers women profile. The investigated number of executives was 26 through an explorer questionnaire and semi-structured interview. It was evidenced that executives of the family-run enterprises in Passo Fundo cultivate values as the honesty, the human being and the companionship; they stay acting in the family-run enterprise for love feeling to the company; their desires or personal dreams are related to the dreams or managerial desires. They present a leadership style more related to people than to tasks; even so they are very guided for the power, assuming a managerial position more based on the masculine model of administration.

Key words: family-run enterprise; executive; feminine gender; management style. 


\section{INTRODUÇÃO}

A sociedade empresarial vivencia um momento de transição, de um modo de produção industrial para um modo de produção ancorado na informação e no conhecimento, com crescimento da participação de mulheres no mercado de trabalho. As organizações, numa perspectiva sistêmica, mantêm permanente interação com essa evolução social. A gestão organizacional, em face do modelo de produção emergente e do atual ambiente de negócios competitivo, dinâmico e complexo, necessita de gerentes transformacionais (Burns, 1978) que levam em conta as preocupações e as necessidades de desenvolvimento de cada funcionário, suas consciências sobre diversas questões, ajudando-os a considerar velhos problemas, a partir de novas perspectivas; que instigam, despertam e inspiram a dedicar esforço extra para o alcance das metas do grupo de trabalho.

A literatura sobre liderança empresarial sugere que homens e mulheres lideram de maneira diferente, apesar de as carreiras gerenciais apresentarem traços característicos comuns à liderança, como inteligência, segurança, sociabilidade, independentemente do sexo (Burns, 1978; Wood, 1997; Peters, 1998; Robbins, 2000). Dado que os homens historicamente detêm a maioria dos postos de liderança nas organizações e são os herdeiros indicados para conduzir os negócios de famílias, emerge a necessidade de compreender o estilo de gestão das mulheres em empresas familiares e analisá-lo em relação aos cargos do conhecimento.

Por estilo de gestão entende-se a maneira ou caráter especial de um gerente exprimir os pensamentos, modo de proceder em qualquer situação de trabalho e que seja capaz de promover a manutenção e desenvolvimento de empresas em ambientes de negócios globalizados. Cargos do conhecimento são postos de trabalho não tradicionais (Crawford, 1994; Drucker, 1995), nos quais as pessoas precisam demonstrar capacidade de aplicar uma informação em trabalho ou resultado específico, por meio do seu cérebro.

Apesar dos avanços ocorridos nas últimas décadas em relação às mulheres que ocupam cargos gerenciais nas empresas, o preconceito e a discriminação ainda são poderosas barreiras à presença feminina nos negócios. A mulher, com maneira de administrar que se confunde entre o estilo masculino e o feminino e apresentando características próprias como humildade, maior estabilidade emocional, objetividade, paciência, auto-renúncia, disposição para operar em ambientes de contrariedade, negociar fazendo menos concessões, e inteligência enriquecida 
pela intuição, está tornando-se indispensável no mundo empresarial contemporâneo (Loden apud Gomes, 1997; Lodi, 1999).

As empresas familiares, aquelas em que o processo sucessório está na segunda geração ou mais, possuem características tradicionais na condução das atividades gerenciais, mais centradas na figura do gênero masculino. A partir dessas reflexões e considerando os desafios impostos às empresas administradas por meio de modelos de gestão tradicionais, o problema de pesquisa foi assim definido: as mulheres executivas que atuam em empresas familiares adotam um estilo de gestão masculino ou feminino?

O objetivo geral do estudo foi identificar se as mulheres executivas se mostram mais propensas a trabalhar sob a ótica do pensamento sistêmico, prevendo os desafios, interagindo com uma gama maior de variáveis e projetando o futuro da empresa e do grupo de trabalho de forma sustentável ${ }^{(1)}$.

Este estudo discute aspectos da sociedade do conhecimento, da gestão centrada no pensamento sistêmico, do perfil e do estilo de gestão de 26 mulheres executivas que trabalham em empresas familiares, localizadas na cidade de Passo Fundo, no Estado do Rio Grande do Sul. Esta análise reflete um esforço de colaboração na criação de um projeto comum, voltado para a disseminação e debate de idéias sobre gestão de empresas familiares, em especial para ampliação de estudos organizacionais, a partir da realidade brasileira. Para tal, primeiramente é delineado o marco teórico-conceitual. Na seqüência é explicitada a metodologia da investigação e a análise e discussão dos resultados da pesquisa de campo.

\section{Marco Referencial Teórico}

A elaboração de uma fundamentação teórica buscou evidenciar a necessidade de a empresa contemporânea repensar os estilos de gerenciamento adotados pelos gerentes, incorporando um papel de gestor de aprendizagem da sua equipe, no próprio local de trabalho, na busca de uma cultura que valorize e promova a aprendizagem contínua. Ela é função da crescente complexidade das operações da empresa, em ambiente de mudança contínua a velocidades crescentes. Admite-se que a capacidade de aprendizagem organizacional será fator diferenciador para a manutenção da competitividade do negócio numa economia global. 


\section{O Conhecimento e a Gestão}

Reconhecer a empresa como espaço para a produção de conhecimento representa uma ruptura de conceitos e estilos gerenciais, arraigados na esfera social e na estrutura produtiva, empresarial e tecnológica. A sociedade do conhecimento, como vem sendo considerada por autores do campo econômico-empresarial (Crawford, 1994; Drucker, 1996; Senge, 1998), requer novos modelos de gestão, que priorizem o homem como participante do processo, da concepção e da execução do trabalho, possibilitando a construção de si mesmo, fazendo do trabalho espaço de crescimento e de auto-realização.

O processo de transformação ora em curso enfatiza a necessidade de combinação do conhecimento tácito e explícito (Schumpeter, 1988; Argyris, 1992), para prover o surgimento de novos produtos e métodos de produção. A função da organização, por sua vez, passa a ser a de colocar o conhecimento para trabalhar em ferramentas, produtos e processos, na concepção do trabalho e no próprio conhecimento, entendido como a capacidade de aplicar a informação a tarefas específicas, habilidade essa encontrada somente nos humanos, seres capazes de aplicar a informação por meio do seu cérebro ou das suas mãos (Crawford, 1994).

Nesse sentido, Senge (1998) propõe a adoção de modelos de gestão que transformem a organização empresarial em uma organização aprendiz, fato possível pela convergência de cinco componentes ou disciplinas que se desenvolvem separadamente: raciocínio sistêmico, domínio pessoal, conscientização dos modelos mentais enraizados, definição de um objetivo comum e disciplina do aprendizado em grupo, porque a unidade fundamental de aprendizagem das organizações modernas é o grupo e não o indivíduo.

Ao contrário dos modelos de gestão clássicos surgidos no período industrial, início do século XX, e estruturados numa família nuclear, com divisões de papéis entre os sexos, instituições imortais que sustentavam o sistema, os novos modelos de gestão priorizam o processo de aprendizagem do indivíduo na organização (Case, 1996; Drucker, 1996).

De acordo com Drucker (1996), a sociedade do conhecimento requer uma organização empresarial que facilite o livre fluxo de informações, que encoraje a utilização plena da capacidade intelectual do indivíduo e que assegure rápida resposta às mudanças. Produtos, procedimentos e formas organizacionais que, no passado, contribuíram para o sucesso dos negócios, tornam-se ineficazes diante da velocidade das mudanças ambientais. $\mathrm{O}$ administrador precisa ser capaz de promover ações transformadoras radicais, seja alterando conceitos, produtos 
e procedimentos, seja refletindo o conjunto de valores e crenças que possui para conduzir sua vida na empresa (Robbins, 2000).

Para atingir o nível de desenvolvimento gerencial requerido pelo novo ambiente empresarial, os administradores precisam resgatar a habilidade de percepção da dinâmica do todo e das interações de suas partes, isto é, o raciocínio sistêmico (Senge, 1998). A capacidade de uma empresa aprender continuamente, que coloca o enfoque sistêmico como sua base, fica vazia de significado, caso sua estrutura não reflita também uma visão sistêmica do negócio. O raciocínio sistêmico é possível, quando o modelo de gestão adotado está arquitetado em torno de processos, favorecendo a mudança na forma de pensar das pessoas, possibilitando que elas adquiram e exercitem uma visão sistêmica da realidade. Disso resulta a dificuldade de implementar um modelo de gestão voltado à produção de conhecimento, haja vista a existência de estruturas organizacionais departamentalizadas e administradores formados com base nos modelos de gestão clássicos, isto é, mecanicistas, e com relação pedadógica enfraquecida no que tange ao trabalho artesanal, que precedeu a Revolução Industrial, momento em que se instituiu o controle e a especialização do trabalho e se perdeu o seu significado intrínseco (Case, 1996; Morgan, 1996).

Embora seja fundamental à organização empresarial o saber-fazer, os gestores precisam prover o ambiente de trabalho de espaços que superem a fragmentação entre aqueles que fazem e aqueles que pensam. O sucesso da empresa contemporânea está diretamente ligado à sua capacidade de criar novas formas de conhecimento e traduzi-lo para a ação, por meio de novas tecnologias incorporadas aos produtos e processos. Mas o conhecimento não está fora da organização. Está latente nela própria, na memória e no potencial de cada funcionário. $\mathrm{O}$ segredo reside em criar um senso de identificação entre o funcionário e a organização, enfatizando a importância de a informação estar livremente disponível a todos, mediante uma estrutura conceitual que os ajude a extrair sentido daquela informação.

\section{A Gestão nas Empresas Familiares}

As funções gerenciais de planejar, organizar, liderar e controlar, preconizadas por Fayol (apud Robins e Coulter, 1998) em face de todas as mudanças de cenário que se processam no mundo empresarial, são consideradas ultrapassadas. A paralisia que o planejamento provocou em muitas empresas em detrimento da ação (Starkey, 1997) revelou que ser apenas gerente, em seu conteúdo clássico, já não é suficiente.

No mundo contemporâneo, as equipes passam a ocupar papel central no de- 
senvolvimento de projetos interdisciplinares, enquanto especialistas de várias áreas do conhecimento se desdobram na utilização máxima de suas competências (Drucker, 1996). Esse pode ser definido como um modelo de gestão pautado na transparência (Case, 1996), por meio do qual as pessoas envolvidas no processo compreendem o seu papel e importância dentro do contexto e buscam transformar a cultura organizacional.

Gerenciar com transparência em empresas familiares, ao contrário das organizações em geral, representa abalo no poder instituído e compartilhamento do patrimônio, não da gestão (Grzybovski e Tedesco, 2000). Tanto o ambiente de trabalho quanto a cultura organizacional instalada estão fortemente ligados à família proprietária. Os administradores se deparam diariamente com conflitos travados entre membros da família proprietária, que repercutem diretamente no processo de tomada de decisão na empresa (Lodi, 1999).

O estilo politicamente correto de gerenciar empresas familiares implica a necessidade de apresentar, ao mesmo tempo, sensibilidade para com as necessidades da família, considerando as histórias, os rituais, os símbolos materiais e a linguagem utilizada, e elevado grau de percepção das transformações ambientais, que podem desestabilizar a organização. Ainda, combinar traços de personalidade que provoquem em todos os funcionários uma sensação de envolvimento e participação, independentemente dos conflitos familiares.

\section{As Mulheres Executivas nas Empresas Familiares}

De acordo com Robbins (2000), o sentimento de participação dos funcionários no ambiente de trabalho emerge da cultura organizacional existente, influenciada pelo estilo de trabalho da alta administração. É um processo administrativo que exige estrutura organizacional e modelo de gestão flexíveis, capazes de mudar a forma de pensar e de interagir dos indivíduos que a ele estão ligados.

Para Senge (1998) o estilo de gestão que deve imperar em organizações contemporâneas e geradoras de conhecimento, isto é, em organizações de aprendizagem, é aquele que permite a conectividade dos objetivos e das estratégias organizacionais, prevendo desafios e não simplesmente reagindo às crises. Essencialmente, é uma organização com executivos capazes de interagir com uma gama maior de variáveis presentes no ambiente, ao mesmo tempo que projetam o futuro de forma sustentável.

Na visão de Lodi (1999) e de outros teóricos citados por Robbins (2000), a gestão empresarial apresenta diferenças significativas, quando aferida ao sexo e aos estilos de liderança. Para Lodi (1999) as mulheres executivas apresentam 
características peculiares nas organizações de aprendizagem. Ao mesmo tempo que preparam e organizam o ambiente familiar, são responsáveis e conseguem conduzir atividades empresariais. Também são flexíveis para adaptar seu comportamento a diferentes situações; são humildes para aceitar situações de desmotivação por período prolongado; apresentam maior estabilidade emocional, apoiada em maturidade psicológica em que são pouco perceptíveis as disritmias; são objetivas e persistentes; demonstram paciência, disposição para começar de baixo, aprender com a modéstia, suportar condições impróprias, bem como maturidade para tarefas de housekeeping, ou seja, administrar serviços sob condições específicas de desempenho e em ambientes estáveis. As mulheres tendem a adotar um estilo de liderança mais democrático, ao passo que os homens se sentem mais à vontade com um estilo diretivo.

“As mulheres encorajam a participação, a partilha do poder e da informação e tentam aumentar a auto-estima dos seguidores. Preferem liderar pela inclusão e recorrem a seu carisma, experiência, contatos e habilidades interpessoais para influenciar os outros. [...] Os homens tendem a adotar mais um estilo diretivo de comando e controle. Recorrem à autoridade formal de seu cargo como base para sua influência. [...] A tendência das líderes do sexo feminino, de serem mais democráticas que os do sexo masculino, diminui quando as mulheres ocupam cargos de dominância masculina. Ao que parece, as normas grupais e os estereótipos masculinos sobre os líderes anulam as preferências pessoais, de tal forma que as mulheres abandonam seus estilos femininos nesses cargos e atuam de modo mais autocrático” (Robbins, 2000, p. 413).

Dado que os homens historicamente assumem cargos de executivos em empresas familiares, é tentador conhecer o estilo de gestão das mulheres que venceram as adversidades, superaram barreiras de gênero, a falta de eficácia na persuasão de outros acionistas poderosos e ressentidos com a sua posição, a resistência de irmãos e parentes à sua ascensão, a lentidão na decolagem inicial ou insegurança em áreas operacionais, isto é, nas atividades-fins, devido ao despreparo pessoal, às relações patronais ou institucionais, lobbying, por exemplo, prejudicadas pelo preconceito quanto ao papel empresarial da mulher.

Para Betiol e Tonelli (1991) há uma geração de mulheres na sociedade brasileira que ainda luta pelo seu reconhecimento. Muitas dessas mulheres atuam em áreas que dizem respeito ao universo feminino: moda, cosméticos, alimentação, roupas infantis. Elas são empreendedoras, donas de seus negócios e não têm de enfrentar a competição direta com os homens por determinados postos nas organizações. 
Segundo as autoras, o caminho para as mulheres executivas não se encontra aberto, sendo-lhes exigido investimento psíquico muito maior do que o investimento das empreendedoras e mais do que a maioria dos homens que buscam o mesmo cargo. Há preconceitos instalados nas entranhas organizacionais no que tange à ascensão profissional da mulher. O primeiro, considerado tradicional, diz respeito às diferenças sexuais com base nas quais a empresa ainda a vê como inferior e desigual para assumir postos de comando. O segundo, encontrado em empresas mais modernas em termos administrativos, é funcional, implicando desconfiança da disponibilidade do investimento da mulher no trabalho.

O sucesso das mulheres nas organizações demanda redimensionamento do desempenho dos papéis tipicamente femininos e está diretamente relacionado à cultura organizacional. Em empresas mais flexíveis, o ingresso/ascensão da mulher é facilitado.

\section{Estilo Feminino de Gestão}

As diferenças nos valores e princípios morais cultuados por homens e mulheres muitas vezes levam estas a preferirem um formato organizacional diferente do tradicional, de estrutura burocrática e rigidez hierárquica, o que permite caracterizar o modelo feminino de gestão como aquele que mais valoriza os indivíduos como seres humanos (Robins e Coulter, 1998). As pessoas são tratadas como portadoras de valores e necessidades individuais; os horários de trabalho são mais flexíveis; o aprimoramento educacional é incentivado.

A flexibilidade apontada anteriormente contrapõe-se à não valorização de oportunismos. Os relacionamentos dentro da organização são valorizados por si só e não como meios formais de alcançar os objetivos organizacionais. O sucesso da carreira é medido em termos de serviços prestados aos outros e não por promoções, quantidade de poder adquirido ou aumentos salariais. Nessas organizações desenvolvem-se as habilidades dos membros e ampliam-se as competências pela oferta de novas oportunidades de aprendizado, ao invés de apenas enfatizar a especialização por meio do desenvolvimento de um leque estreito de especialidades; é o compromisso com o crescimento do empregado.

De acordo com o perfil descrito, a mulher consegue construir um sentimento de comunidade, por meio do qual os membros da organização se unem, e aprendem a acreditar e a cuidar uns dos outros. As informações são compartilhadas e todos os que serão afetados por uma decisão têm a oportunidade de participar da tomada desta decisão.

Geralmente, esse modelo de gestão é encontrado em organizações eficazes e 
essencialmente administradas por mulheres, entre os quais se encontram os abrigos para mulheres vítimas de violência, clínicas de atendimento médico à mulher e firmas que vendem produtos diretamente ao público feminino (Robins e Coulter, 1998).

Raros são os casos em que a mulher conseguiu ascender aos cargos diretivos de organizações geridas por homens. Para Lodi (1999) a ascensão da mulher como presidente do conselho ou da empresa é uma exceção, facilmente perceptível em todo o mundo. A regra geral é alguém do sexo feminino chegar ao cargo máximo como resultado de um infortúnio: morte do fundador, marido ou pai, ou pela inabilidade dos concorrentes masculinos familiares. Por outro lado, sucessão não está diretamente ligada à inteligência, senso prático, intuição, integridade, competência ou grau de escolaridade, mas pode estar ligada à capacidade de articulação política. Enquanto as mulheres procuram métodos oficiais e formais de promoção, os homens apóiam-se na rede de amizades masculinas.

As possíveis explicações para as mulheres não aspirarem tanto aos cargos de presidência como os homens, residem na especificidade da área em que atuam e no grau de dedicação à organização. As mulheres atuam mais em áreas humanas, como relações públicas, recursos humanos e comunicações, áreas em que raramente são escolhidos os presidentes. Os homens estão mais disponíveis para dedicação total à carreira; mas nem sempre o fazem, por não terem os compromissos de maternidade, criação de filhos e administração da casa; gravidez e filhos pequenos favorecem a escolha de trabalho em tempo parcial, interrupção de carreira ou procura de cargos menos desafiantes (Lodi, 1999).

Importante considerar que, uma vez no topo, as mulheres não se confessam felizes com o sucesso. As maiores recompensas ainda são para o estilo mais agressivo, estressante, espetacular e masculino. As mulheres americanas, por exemplo, procuram trabalhar em pequenas empresas de hierarquia mais permeável ou fundar o seu próprio negócio, no qual as pessoas podem sentirse construtoras e não assessoras. Isso deixa transparecer que as mulheres não buscam apenas cargos decorativos. Buscam espaços em ambientes competitivos, onde o que interessa são os resultados, diante de forte preconceito cultural.

\section{Método e Contexto da Pesquisa}

A carência de maior sistematização do tema abordado conduziu o presente trabalho a assumir as características de um estudo exploratório, ampliando o 
conhecimento empírico do problema e sendo possível constituir um estudo inicial para futuras pesquisas descritivas, que outros estudiosos poderão desenvolver.

A profundidade que se buscou para entender o estilo de gestão das mulheres executivas, bem como a natureza multidisciplinar requerida pelo tema, levou à opção do método quali-quantitativo, do ponto de vista da função aprendizagem organizacional.

O universo da presente pesquisa são as empresas privadas relacionadas no Relatório de Atividades dos Contribuintes da Prefeitura Municipal de Passo Fundo, de 1998, fundadas há mais de 25 anos, classificadas por tipo de gestão (familiar, não familiar), que na época da coleta de dados somavam 155 organizações. Foram relevantes para a investigação somente as empresas sob gestão familiar, com membros da família proprietária, no mínimo representando a segunda geração.

A amostra foi composta por 26 mulheres executivas de empresas familiares da cidade de Passo Fundo, no Estado do Rio Grande do Sul, identificadas a partir de questionário estruturado aplicado em 155 empresas selecionadas. As mulheres executivas foram investigadas por meio de questionário estruturado e entrevista semi-estruturada. Adotou-se a técnica de investigação composta por um número mais ou menos elevado de questões apresentadas por escrito às pessoas, tendo por objetivo o conhecimento de opiniões, crenças, sentimentos, expectativas etc.

Os dados dos questionários foram submetidos à tabulação de acordo com a escala nominal, para identificar categorias, como origem familiar, grau de parentesco com o fundador, grau de instrução, estado civil, e a escala de intervalo, compreendendo faixa etária e jornada de trabalho. Os dados das entrevistas foram submetidos à análise de conteúdo (Bardin, 1979; Minayo et al., 1996), ao estabelecimento de categorias e à construção de figuras com dados percentuais. Nas entrevistas semi-estruturadas foram aplicados dois testes referentes ao estilo de liderança (Leadership Questionnaire) e à orientação ao poder (Studies in Machiavellianism), propostos por Robbins (2000).

\section{Resultados da Pesquisa}

Nesta seção são descritos e analisados os dados da pesquisa exploratória. Inicialmente é feita uma análise descritiva das empresas e, em seguida, do perfil e estilo de gestão das mulheres executivas atuantes em empresas familiares. 


\section{Perfil das Empresas Familiares}

Do total de 155 empresas selecionadas, 47,10\% foram as respondentes, 38,6\% não foram localizadas e 14,84\% recusaram-se a responder ao questionário. Das empresas respondentes, 86,30\% atuam no comércio; 69,86\% são empresas familiares; 24,66\% são empresas da família; 5,48\% são empresas não familiares.

Os descendentes de italianos são responsáveis por 60,78\% das empresas familiares, seguidos pelos descendentes de alemães e brasileiros (15,68\%). Outras etnias, como espanhola, polonesa, síria (5,7\%) e austríacos (3,92\%) também foram encontradas.

Devido à colonização do Rio Grande do Sul ter sido realizada por grande número de imigrantes italianos com características empreendedoras latentes, moldadas no modelo de gestão masculino, no qual a figura masculina é central, observou-se que Passo Fundo mantém essa cultura. As mulheres aparecem em 62,75\% das empresas familiares, um percentual altamente significativo em termos de mercado empresarial. A maior concentração de mulheres (81,25\%) está no comércio; nos ramos industrial e de prestação de serviços foi encontrado 6,25\% de mulheres, respectivamente.

Os membros da família atuantes na empresa, por gênero, são representados por $71,86 \%$ de homens e $28,14 \%$ de mulheres (vide Figura 1). A presença feminina é maior nas empresas, cuja família proprietária é de origem italiana (53,19\%) e alemã (17,2\%). Grande parte das mulheres atuantes nessas empresas são filhas dos fundadores $(44,68 \%)$ ou esposas $(36,17 \%)$.

Figura 1: Membros da Família em Atividades nas Empresas Familiares, por Gênero

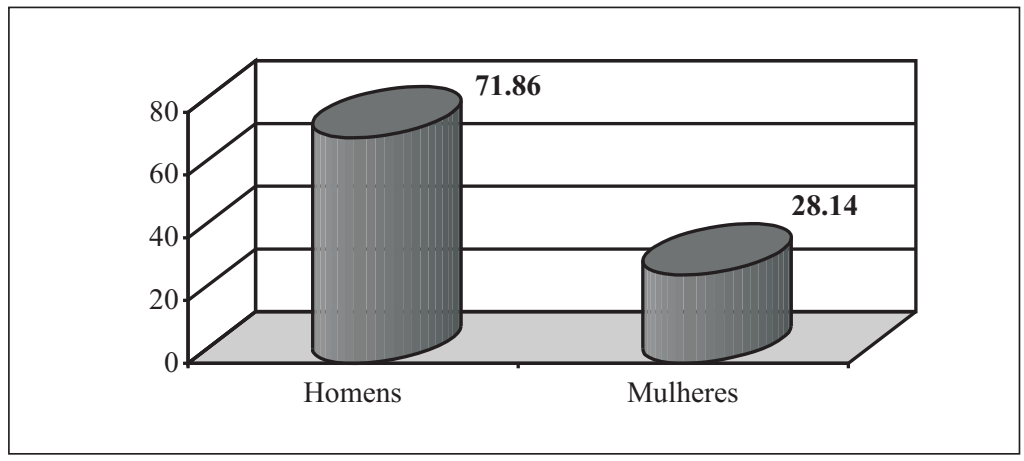

Fonte: pesquisa de campo (2000). 
Quanto aos cargos ocupados pelas mulheres das famílias empreendedoras, percebe-se que mais da metade delas se encontram na cúpula administrativa, ocupando cargos de gerência (38,30\%) ou de diretoria (19,15\%). Nos cargos operacionais - fazendo um pouco de tudo - encontram-se $12,77 \%$ das mulheres que, apesar de figurarem como sócias, exercem cargos subalternos: secretária, vendedora, faxineira, ajudante de cozinha. Observa-se que ainda é restrita a presença de mulheres em cargos de diretoria, com acúmulo de poder de decisão.

Confirma-se a ausência de Conselhos de Administração ou Conselhos de Família em empresas familiares. Há desconhecimento do funcionamento desses órgãos, o que compromete a transição de gerações da família na empresa. A ausência de regras e códigos de conduta para membros da família marcou a destruição de impérios empresariais no Brasil.

Como apresentado na Tabela 1, o segmento supermercados concentra o maior número de mulheres $(22,58 \%)$ exercendo cargos gerenciais, seguido pelos segmentos menos tradicionais para o gênero feminino, como combustíveis e lubrificantes (12,90\%) e moveleiro (12,90\%). Tais dados surpreendem, por representarem a quebra de paradigmas, pois até recentemente eram caracterizados como empreendimentos ligados à atuação de homens.

Tabela 1: Executivas Atuantes nas Empresas Familiares de Passo Fundo, por Segmento

\begin{tabular}{l|c|c}
\hline Executivas atuantes por segmento & N. ocorrências & $\%$ \\
\hline Supermercado & 07 & 22,58 \\
\hline Madeireiro/Moveleiro & 04 & 12,90 \\
\hline Combustíveis e Lubrificantes & 04 & 12,90 \\
\hline Calçados e Confecções & 03 & 9,68 \\
\hline Transporte de pessoas & 03 & 9,68 \\
\hline Metalurgia & 02 & 6,45 \\
\hline Joalheria & 02 & 6,45 \\
\hline Outros & 04 & 19,37 \\
\hline Total & 31 & 100,00 \\
\hline
\end{tabular}

Fonte: pesquisa de campo (2000).

A pesquisa exploratória revelou a presença significativa de mulheres, filhas dos fundadores, nas empresas familiares, o que possibilita a continuidade dos empre- 
endimentos mediante a consolidação do processo sucessório, independentemente do segmento de atuação ou da presença de filhos homens.

\section{Perfil das Mulheres Executivas}

Das 31 mulheres executivas atuantes nas empresas familiares de Passo Fundo, 26 disponibilizaram-se a participar da investigação, representando 83,87\% de respondentes.

Como já referenciado anteriormente, há duas faixas etárias distintas de mulheres executivas: filhas e esposas dos fundadores. A predominância é de mulheres na faixa etária de 30 a 49 anos, filhas dos fundadores, e na faixa etária acima de 50 anos, esposas dos fundadores. Ambas representam 34,62\% das mulheres executivas entrevistadas (vide Figura 2).

\section{Figura 2: Mulheres Executivas nas Empresas Familiares, por Faixa Etária}

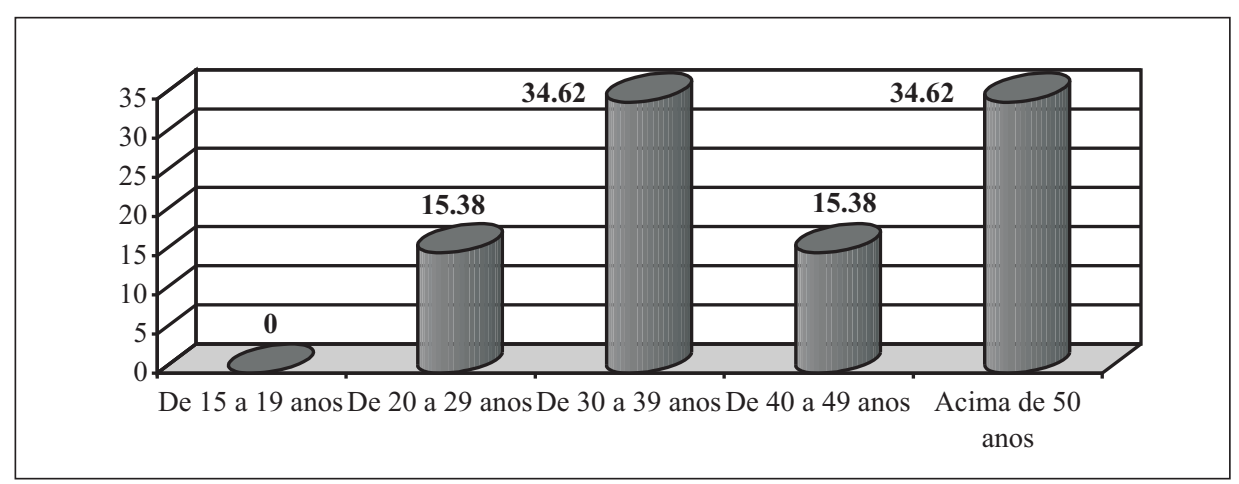

Fonte: pesquisa de campo (2000).

O grau de instrução superior de 53,85\% das mulheres executivas retrata a busca pelo aprimoramento técnico. Em empreendimentos de menor porte, constatou-se a maior incidência de mulheres com o grau de instrução inferior ao primeiro grau completo (19,23\%), como se observa na Figura 3. Quanto maior a complexidade das empresas, maior é o grau de exigência de qualificação exigido da mulher para assumir os negócios. 


\section{Figura 3: Mulheres Executivas nas Empresas Familiares, por Grau de Instrução}

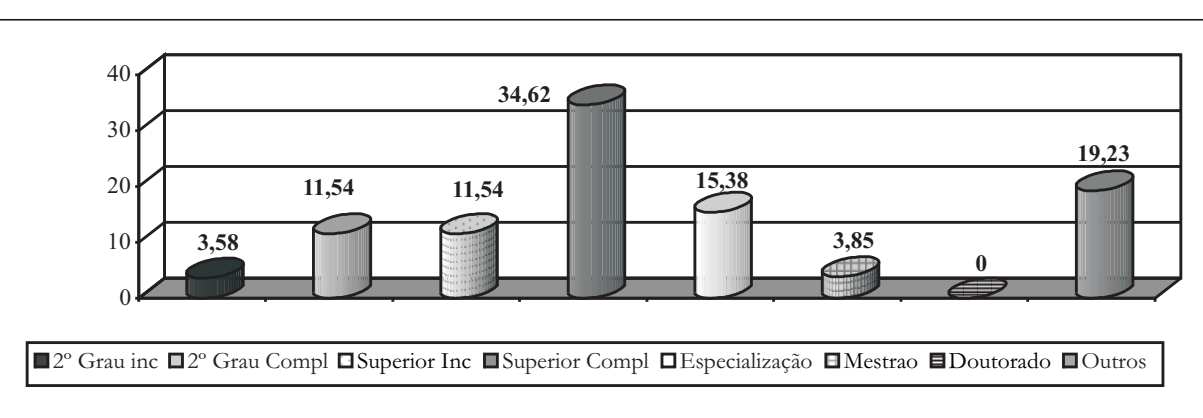

Fonte: pesquisa de campo (2000).

Entre os cursos de formação acadêmica escolhidos pelas executivas, há preponderância (35,71\%) da faculdade de Administração, seguido por Psicologia e Artes Plásticas, com 14,29\% respectivamente (vide Figura 4).

\section{Figura 4: Formação Acadêmica das Mulheres Executivas}

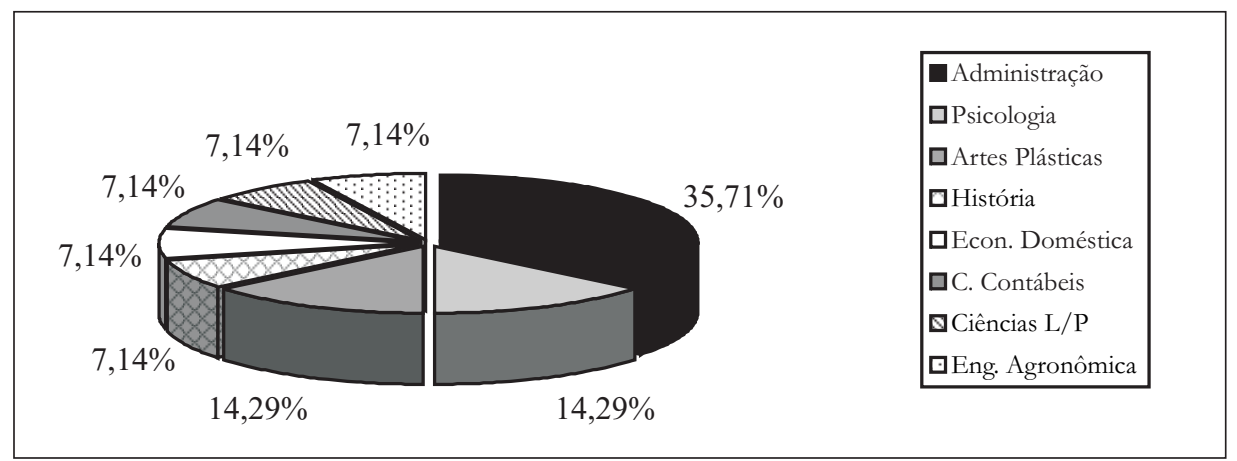

Fonte: pesquisa de campo (2000).

As executivas justificam a escolha da faculdade de Administração pelo grande interesse em compreender os matizes da atividade que exercem. Declara uma das entrevistadas: "o mundo empresarial é fascinante e perigoso, concomitantemente. Raras vezes compreendemos os caminhos que trilhamos. A clareza só vem com os anos de experiência. Assim valorizamos nossos pais e os ouvimos. Tentamos suprir a ausência de conhecimento empírico com os cursos de especialização”. Tais cursos focalizam o aprimoramento das técnicas de gestão. São eles: Moderna Gestão Empresarial, Gestão Estratégica Empresarial, Psicologia Clínica, Controladoria e Administração de Recursos Humanos. 
Ouve-se muito falar em receios na contratação da mulher devido ao seu comprometimento com as atividades domésticas. Nesse sentido, comprovou-se a dupla jornada de trabalho das mulheres executivas, que corresponde a até 8 horas diárias na empresa (65,38\%) e até 6 horas diárias em casa (96,15\%), como revela a Figura 5. Algumas mulheres declararam, ainda, que além do trabalho na empresa e em casa, exercem outras atividades, como de professora, supervisora, avaliadora e em entidades de classe.

\section{Figura 5: Jornada de Trabalho da Mulher Executiva na Empresa e em Casa}

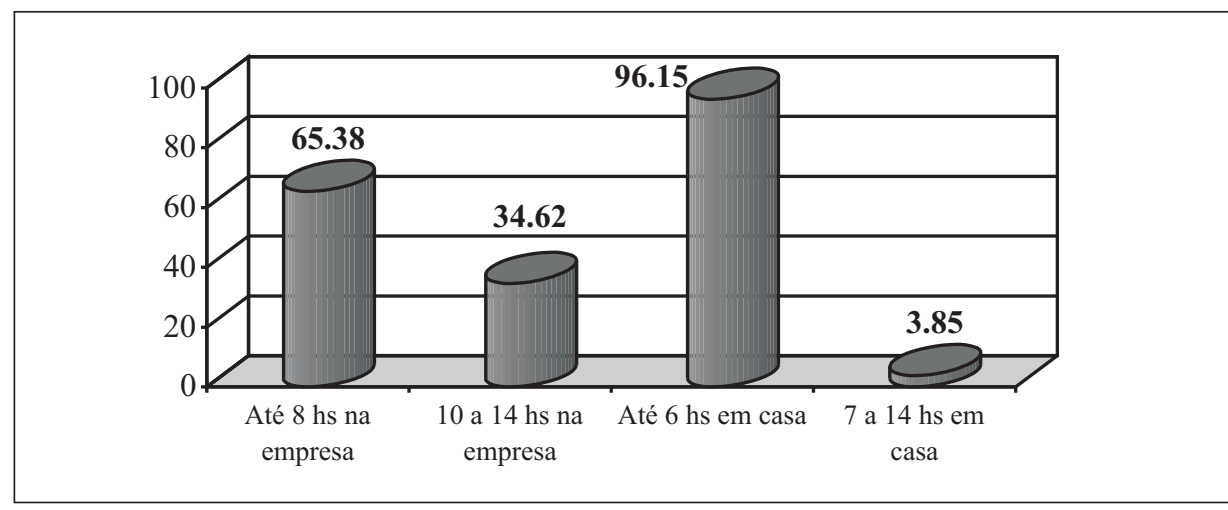

Fonte: pesquisa de campo (2000).

Cerca de 15,38\% dedicam algumas horas de seu tempo a instituições ou organizações sem fins lucrativos. Ao contrário do que se pressupõe do comportamento da mulher executiva, poucas horas são dedicadas para tais atividades. "Isso eu deixo para aquelas que não tem nada a fazer. Se fizer ainda essa atividade, não suportarei”, declara uma empresária. O tempo livre, quando há, é destinado ao aprimoramento técnico ou à busca da proficiência em outro idioma (inglês, espanhol ou italiano).

Mesmo demonstrando pouca familiaridade com as ferramentas computacionais, $65,38 \%$ das executivas utilizam computador, $61,54 \%$ acessam a Internet, 76,92\% usam TV a cabo e celular e 84,62\% usam fax (vide Figura 6). As diversas tecnologias disponíveis para a comunicação não são consideradas para a prática do comércio (e-business); a utilização é restrita à comunicação, consultas de preços e envio de mensagens. 
Figura 6: Utilização de Recursos Tecnológicos

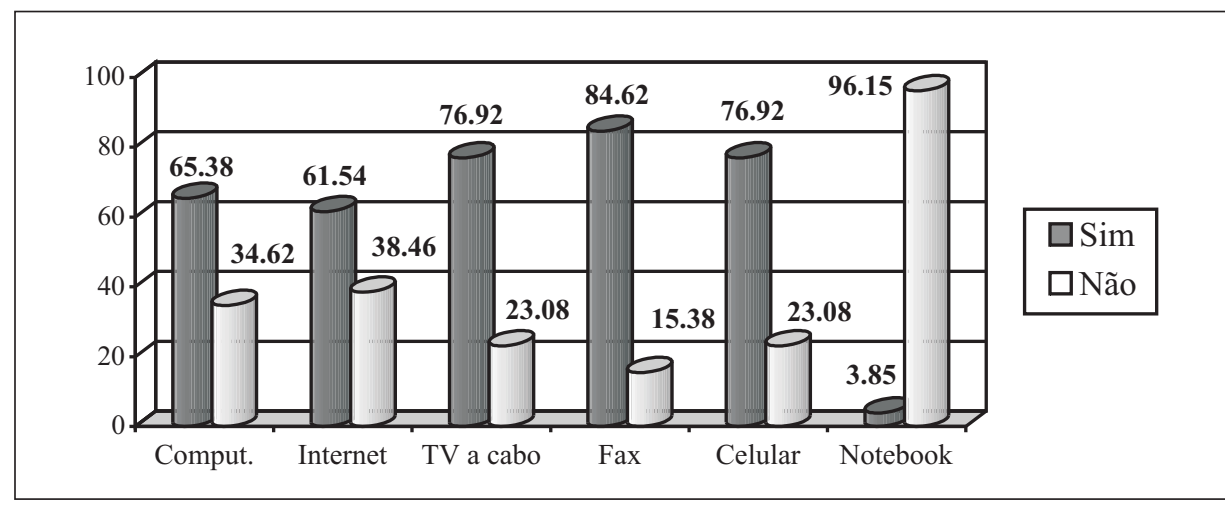

Fonte: pesquisa de campo (2000).

Quanto ao estado civil das executivas, as mulheres casadas e com filhos representam a maioria ou 57,69\%, enquanto as solteiras sem filhos representam 19,23\%. As primeiras não se consideram "chefe de família" (53,85\%) e afirmam que as atividades e o orçamento domésticos são partilhados pelo casal; não há "chefe" mas uma "união familiar".

\section{Categorização das Executivas}

A entrevista semi-estruturada realizada com as executivas permitiu a identificação do estilo de gestão preponderante. Para o agrupamento de respostas comuns utilizaram-se os subsídios teóricos de Minayo et al. (1996) e Bardin (1979).

Cultuando valores como fidelidade, honestidade, sinceridade, valorização e respeito ao ser humano, companheirismo, lealdade e reciprocidade aos estímulos ofertados, a mulher executiva é um misto de carinho, confiança e lealdade.

Quanto à política de recursos humanos que, segundo Chiavenato (1994), se refere à maneira pela qual a organização pretende lidar com seus membros e por intermédio deles atingir os objetivos organizacionais, permitindo condições para o alcance de objetivos individuais, 50\% das respondentes disseram que a adotam.

As respostas diversas e desconexas de um possível conjunto não permitiram o agrupamento de respostas, mas desvelaram que as mulheres estão mais voltadas à operacionalização do que ao gerenciamento estratégico da empresa. Elas consideram como política de recursos humanos as categorias de recrutamento e seleção, treinamento e testes avaliativos, enquanto, na realidade, as polí- 
ticas situam o código de valores éticos da organização que, através delas, governam as relações com os stakeholders internos e externos.

Dos recursos humanos, as executivas exigem, por ordem de importância, profissionalismo e comprometimento, honestidade e confiança, boa aparência, pontualidade e educação, oferecendo, em contrapartida, cursos e treinamentos para capacitação profissional e oportunidades de crescimento pessoal. Para a seleção de colaboradores, as mulheres levam em conta a competência profissional do candidato, não considerando a masculinidade ou feminilidade do cargo.

Na empresa da família, que conduzem como se família fosse, permanecem por amor à empresa, para cumprir a missão familiar e por competência e capacidade. Para tanto, utilizam estratégias como constante atualização, aprimoramento e especialização por meio de cursos, dedicação à empresa, competência e, por considerarem-se a base da família, independentemente da forma de ingresso: missão familiar, morte do fundador, casamento.

Dessa forma, seus desejos e/ou sonhos pessoais são rejeitados em detrimento dos sonhos e desejos empresariais, tendo como respostas mais evidentes o progresso da empresa e o crescimento profissional. As executivas buscam satisfazer os desejos e/ou sonhos mediante trabalho, perseverança, dedicação e planejamento. Os sentimentos que norteiam suas ações são o amor, a honestidade e a justiça. As demais respostas, como satisfação, realização pessoal, fazer correto e da melhor maneira, preservar a memória do pai, apontam uma confusão entre sentimentos profissionais e pessoais.

Diante do questionamento que buscava separar a mulher da executiva, elas mostraram-se reflexivas. "Eu nunca me havia perguntado isso! Não sei o que responder!” As executivas, batalhadoras, felizes, realistas, realizadas e responsáveis, como se definiram, quando submetidas ao Leadership Questionnaire e ao Studies in Machiavellianism, desvelaram os dados apresentados nas Figuras 7 e 8. A Figura 7 apresenta as respostas referentes ao Grupo A, composto por doze questões que indicam o grau de orientação para tarefas. A Figura 8 apresenta as respostas referentes ao Grupo B, composto por dez questões, que indicam o grau de orientação para pessoas. O cruzamento dos dois indicadores permitiu identificar a orientação dada (pessoas ou tarefas) e definir o estilo de liderança (masculino ou feminino). 
Figura 7: Estilo de Liderança - Grupo A

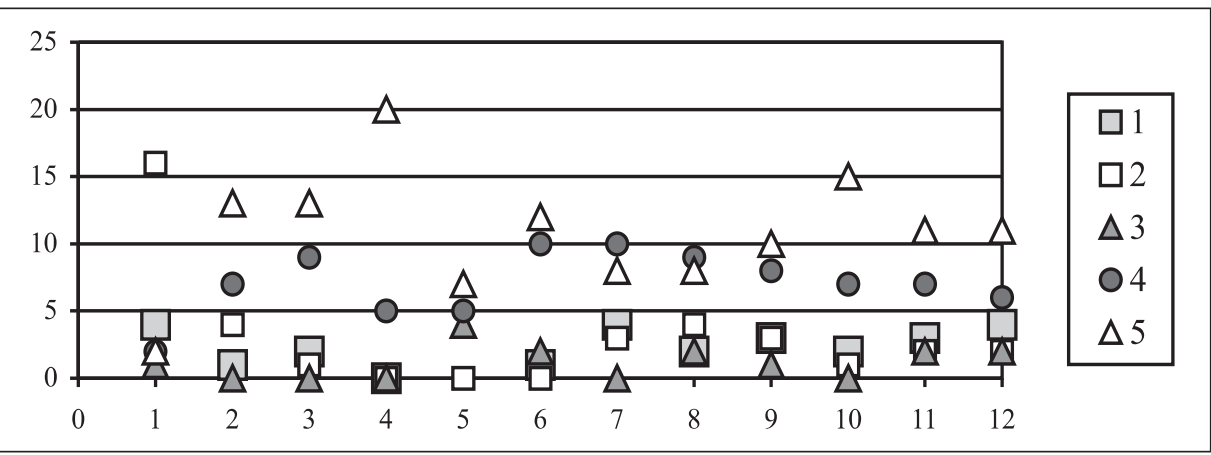

Fonte: pesquisa de campo (2000).

Figura 8: Estilo de Liderança - Grupo B

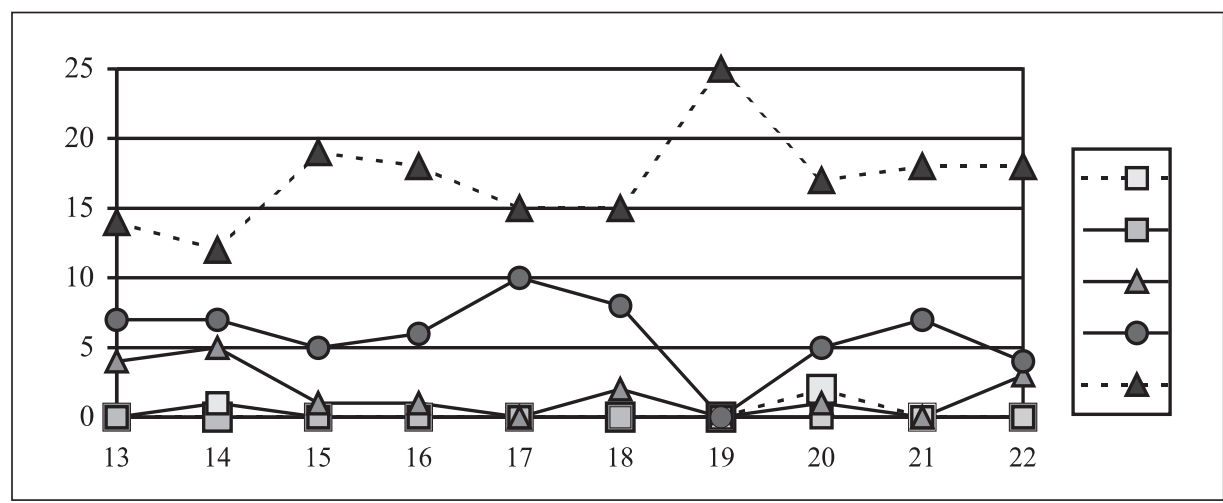

Fonte: pesquisa de campo (2000).

A pontuação obtida por meio das respostas das executivas referentes ao teste Estilo de Liderança é demonstrada na Figura 9. O resultado é de dez respostas com pontuação inferior a 47 pontos e quinze respostas superiores a 47 pontos, completando o Grupo A. Uma pontuação superior a 47 pontos indica muita orientação para a tarefa; porém o número de respostas referentes ao Grupo B indica muita orientação para pessoas, uma vez que houve 24 respostas com pontuação superior a 40 pontos. 
Figura 9: Estilo de Liderança

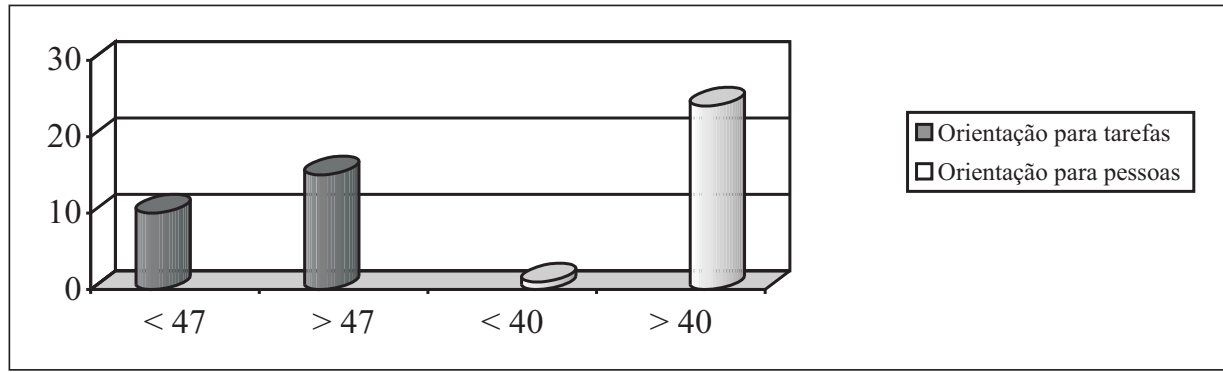

Fonte: pesquisa de campo (2000).

Comparando-se as respostas do Grupo A com as do Grupo B, percebe-se que a orientação para pessoas é muito maior do que a orientação para tarefas. Podese dizer que as executivas entrevistadas adotam estilo de liderança voltado para as pessoas. Segundo Robins e Coulter (2000) a dimensão pessoa abrange ações como desenvolver boas relações interpessoais, ser amistoso e acessível e estar preocupado com problemas pessoais dos funcionários. A dimensão tarefa refere-se a ações como enfatizar a realização das metas do grupo, definir e estruturar atribuições dos membros do grupo e cumprir prazos.

A orientação para o poder revelou uma concentração de respostas entre 25 e 28 pontos, dispostas num intervalo de 14 a 33 pontos, retratadas na Figura 10. Há maior concentração de respostas acima de 25 pontos, revelando forte orientação para o poder, com características de maquiavelismo, manipulação e elevado poder de convencimento. O cruzamento dos dados desvela uma executiva flexível no seu estilo de liderança, porém muito orientada para o poder. Isso aponta um estilo de gestão com base mais masculina do que feminina.

Figura 10: Orientação para o Poder

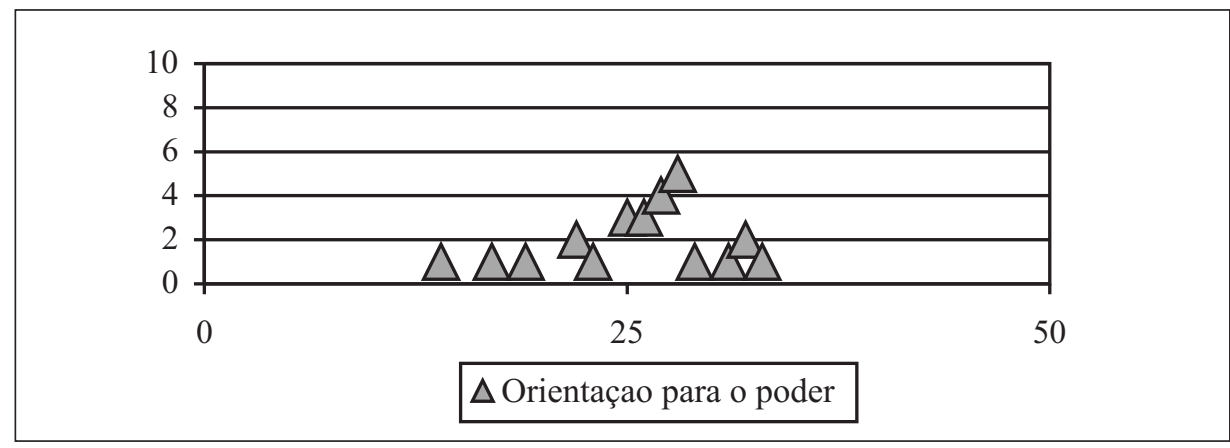

Fonte: pesquisa de campo (2000). 


\section{Discussão dos Resultados}

As mulheres executivas das empresas familiares passo-fundenses podem ser classificadas em duas categorias de faixa etária. As executivas mais jovens, com idade entre 30 e 39 anos, são as filhas dos fundadores; as executivas com idade acima de 50 anos são esposas dos fundadores. Em muitos casos evidenciou-se o trabalho conjunto de mãe e filha. Elas têm um grau de instrução formal de nível superior, em especial na área gerencial, demonstrando que a mulher se prepara para gerenciar a empresa familiar.

Na maioria, são mulheres de descendência italiana e alemã, que atuam em empreendimentos comerciais, ocupando cargos de gerência. Ingressaram na empresa por sucessão e/ou para cumprir sua missão familiar; são casadas e têm filhos, cumprindo dupla jornada de trabalho. Estão mais voltadas para o trabalho empresarial e apresentam restrito envolvimento com instituições sem fins lucrativos. Quando o fazem, buscam o retorno social à empresa e não por benemerência pessoal.

Quanto ao estilo de gestão, pode-se dizer que as executivas das empresas familiares passo-fundenses cultivam valores como honestidade, apreciação do ser humano e companheirismo. Proporcionam aos seus recursos humanos oportunidades de crescimento tanto profissional como pessoal, exigindo em troca profissionalismo e comprometimento, honestidade e educação. Ao contratarem pessoas para o quadro de trabalho, não levam em consideração a masculinidade ou a feminilidade do cargo e sim a competência pessoal.

Elas permanecem atuando na empresa da família em função do sentimento de amor à empresa, por missão familiar e por competência; mas, para manterem-se no cargo, utilizam estratégias como constante atualização, dedicação à empresa e competência, e também por se considerarem a base da família.

Os seus desejos e/ou sonhos pessoais estão relacionados aos desejos e/ou sonhos empresariais, ou seja, ao crescimento da empresa e ao crescimento profissional. Buscam satisfazê-los por meio de muito trabalho, perseverança, dedicação e planejamento. As suas ações são norteadas pelos sentimentos de amor, honestidade e justiça; podem ser definidas como mulheres batalhadoras, felizes e realizadas. Apresentam estilo de liderança mais voltado para as pessoas do que para as tarefas, porém são muito orientadas para o poder. 


\section{Considerações Finais}

Discutir a questão dos gêneros masculino e feminino no ambiente empresarial é tema encantador, por desvelar, em cada discussão, um novo tabu, preconceito ou estímulo. Empiricamente o estudo já apontava a mulher como sendo o gênero em ascensão no mercado de trabalho. Os dados apresentados neste trabalho comprovam que o ambiente empresarial requer cada vez mais relações em detrimento de transações, mediante a busca de harmonia vinculada à mulher, que representa tão bem este papel no ambiente doméstico.

Com capacidade de criar empatia e colocar-se no lugar do outro, a executiva mostra-se capaz de identificar problemas por antecipação. Isso não significa dizer que a sua presença por si só é suficiente. Os sexos se completam também no ambiente empresarial. Enquanto o homem tende à ação com menos opções, a mulher apresenta campo maior de investigação e gera múltiplas alternativas para solucionar um único problema.

As mulheres investigadas comprovaram que também sabem usar um estilo mais rígido, descaracterizando o sexo frágil, que marcou toda a sua história. Mesmo enfatizando fidelidade e honestidade, o companheirismo e a reciprocidade sempre se fizeram presentes, ou seja, o comprometimento está sempre associado a alto grau de confiança, fatores determinantes na construção de um modelo de gestão capaz de promover a aprendizagem de toda a organização ou learning organization.

Dentro desse contexto, organizações empresariais, mesmo de base familiar, gerenciadas por mulheres, têm mais possibilidade de implementar a transparência e o compartilhamento do patrimônio. As executivas são capazes de promover um ambiente que provoque a sensação de envolvimento, de trabalho em equipe, que permite assimilar mais rapidamente novas técnicas, novas experiências e/ou filosofias.

As empresas familiares passo-fundenses gerenciadas por mulheres, mostramse mais propensas a trabalhar sob a ótica do pensamento sistêmico, prevendo os desafios, interagindo com uma gama maior de variáveis e projetando o futuro de forma sustentável. Com muita orientação para o poder, a executiva está disposta a negociar e, utilizando os mesmos recursos do gênero masculino (rigidez), faz menos concessões.

Conclui-se ainda que as mulheres executivas em empresas familiares passofundenses apresentam estilo de liderança mais voltado para as pessoas do que para as tarefas, porém estão muito orientadas para o poder. Elas assumem uma 
postura de liderança que permite afirmar que gerenciam a empresa com o estilo masculino, embora a maioria não perceba o seu estilo de gerenciamento, nem que ele oscila entre o estilo masculino e feminino.

\section{Nota}

${ }^{1}$ A primeira versão do presente trabalho foi apresentada como monografia de conclusão do Curso de Administração de Roberta Boscarin, sob a orientação das demais autoras. O projeto é parte integrante das pesquisas desenvolvidas no Centro Regional de Economia e Administração da Universidade de Passo Fundo.

\section{ReferênCIAs Bibliográficas}

BARDIN, L.

Análise de conteúdo. Lisboa: Edições, 1979.

BETIOL, M. I. S.; TONELLI, M. J.

A mulher executiva e suas relações de trabalho. Revista de Administração de Empresas, v. 31, n. 4, p. 17-33, out./dez. 1991.

BURNS, J. M.

Leadership. New York: Harper \& Raw Publishers, 1978.

\section{CASE, J.}

Open-book management: gerenciamento transparente. Rio de Janeiro: Ediouro, 1996.

CHIAVENATO, I.

Recursos humanos. São Paulo: Atlas, 1994.
CRAWFORD, R.

Na era do capital humano: o talento, a inteligência e o conhecimento como forças econômicas seu impacto nas empresas e nas decisões de investimento. São Paulo: Atlas, 1994.

DRUCKER, P. F.

Administrando em tempos de grandes mudanças. 3. ed. São Paulo: Pioneira, 1996.

GOMES, M. T.

Abaixo os homens? Exame. São Paulo: Abril, v. 31, n.16, p.116-124, jul. 1997.

GRZYBOVSKI, D.;

TEDESCO, J. C.

Empresa familiar: tendências e racionalidades em conflito. 2. ed. Passo Fundo: EDIUPF, 2000. 
LODI, J. B.

Fusões e aquisições: o cenário brasileiro. Rio de Janeiro: Campus, 1999.

MINAYO, M. C. et al. (Orgs.).

Pesquisa social: teoria, método e criatividade. 5. ed. Petrópolis: Vozes, 1996.

MORGAN, G.

Imagens da organização. São Paulo: Atlas, 1996.

ROBBINS, S. P.

Administração: mudanças e perspectivas. São Paulo: Saraiva, 2000.

ROBINS, S. P.;

COULTER, M.

Administração. 5. ed. Rio de Janeiro: PHB, 1998.
SENGE, P. M.

A quinta disciplina. 2. ed. São Paulo: Best Seller, 1998.

SIMONETTI, E. G.

Elas venceram. Veja. São Paulo: Abril, p.125-132, nov. 2000.

STARKEY, K.

Como as organizações aprendem: relatos de sucesso das grandes empresas. São Paulo: Futura, 1997.

SULLIVAN, T.

Procura-se um marido disposto a mudar. América Economia, n. 148, p. 55, dez. 1998.

WOOD, J. D.

As duas faces da liderança - o domínio da administração. Gazeta Mercantil, São Paulo, dez. 1997. n. 17. 